\title{
Enteroparasitosis Prevalence and Parasitism Influence in Clinical Outcomes of Tuberculosis Patients with or without HIV Co-Infection in a Reference Hospital in Rio de Janeiro (2000-2006)
}

\author{
Luanda M.S. Neto ${ }^{1}$, Raquel de Vasconcellos Carvalhaes de Oliveira ${ }^{3}$, Paulo Renato Totino ${ }^{4}$, Flavia Marinho Sant'Anna ${ }^{2}$, Viviane \\ de Oliveira Coelho ${ }^{2}$, Valeria Cavalcanti Rolla ${ }^{2}$ and Graziela M. Zanini ${ }^{1}$ \\ ${ }^{1}$ Laboratório de Parasitologia at Instituto de Pesquisa Clínica Evandro Chagas (IPEC) - Fiocruz; ${ }^{2}$ Laboratório de Pesquisa Clinica em \\ Micobacterioses, Instituto de Pesquisa Clínica Evandro Chagas (IPEC) - Fiocruz; ${ }^{3}$ Serviço de Estatística e Documentação, Instituto de Pesquisa \\ Clínica Evandro Chagas (IPEC) - Fiocruz; ${ }^{4}$ Laboratório de Malária at Instituto Oswaldo Cruz (IOC) - Fiocruz; Rio de Janeiro, RJ, Brazil
}

\begin{abstract}
Tuberculosis and intestinal parasites affect primarily low social and economic level populations, living clustered in precarious habitational settings. One of the interesting aspects of this interaction is the parasitism influence in cellular response to tuberculosis. In the present study, we evaluated the prevalence of enteroparasitosis in tuberculosis patients, HIV-infected and non HIV infected, and we observed the influence of helminth presence in the response to tuberculin skin test (TST) and tuberculosis clinical outcomes. From 607 clinical records reviewed, 327 individuals met the study inclusion criteria and did not present any exclusion criteria. The prevalence of enteroparasites observed was $19.6 \%$. There was no significant association among TST result and the variables related to the presence of: helminthes, protozoa, and stool test for parasites result ( $\mathrm{p}>\mathbf{0 . 5})$. Considering the survival of this cohort, we may observe that there is no significant difference $(p>0.05)$ between the survival curves of parasited and non parasited individuals. Solely the variable "eosinophils" presents a statistically significant association $(\mathbf{p}<0.001)$ with helminthes, all other associations are considered not significant. Our findings neither show an association between helminthic infection and a favorable tuberculosis outcome, nor between parasitism and TST response, unlike other in vitro studies. Apparently, experimental data do not correspond to the clinical findings.

Key-Words: Tuberculosis, intestinal parasites, tuberculin skin test, survival.
\end{abstract}

Human tuberculosis is an infectious and contagious disease caused primarily by the Mycobacterium tuberculosis, an aerobic pathogenic mycobacterium infecting primarily the lungs. The progression of $M$. tuberculosis infection is ruled by the host's immune system, and may result in: Immediate elimination of the mycobacterium, latency or immune system failure, leading to the development of active disease [1].

The year of 2005 totaled 1.6 million of deaths by tuberculosis all over the world, including 195,000 with HIV co-infection [2]. One out of three HIV infected individuals has M. tuberculosis co-infection [3], due to the increase of susceptibility to infection and risk to disease progression caused by immunodeficiency [4,5]. Brazil is the $15^{\text {th }}$ country in highest number of tuberculosis (TB) cases [2]. In 2005, the number of cases was 80,632. In the same year, the city of Rio de Janeiro presented an incidence rate of tuberculosis of 92.22 cases/100,000 individuals, and the state has the highest incidence in Brazil [6].

Parasitic infections affect the nutritional status of the individual leading to immunological alterations that promote a decrease in the efficacy of the immune response, favoring the occurrence of other bacterial infections [7]. Tuberculosis and enteroparasitosis affect primarily low social and economic level populations, living clustered in precarious habitational settings [5].

Received on 18 May 2009; revised 20 November 2009.

Address for correspondence: Dr.Graziela Maria Zanini. Av. Brasil, 4365. Manguinhos. Rio de Janeiro/ RJ - Brazil. Zip code.: 21040-900. Phone 3865-9507. E-mail: graziela.zanini@ipec.fiocruz.br. This work was supported with funds from the Brazilian Research Council (CNPq).

The Brazilian Journal of Infectious Diseases 2009;13(6):427-432. (C) 2009 by The Brazilian Journal of Infectious Diseases and Contexto Publishing. All rights reserved.
It is estimated that in the world approximately 3.5 billion people are infected by parasites, among which 450 million would be symptomatic, mostly children. Each year approximately 65,000 deaths occur due to Ancylostomidae, 60,000 associated with Ascaris lumbricoides infection and 70,000 due to Entamoeba histolytica invasive forms [8]. A study in Brazil showed a 55.3\% prevalence of enteroparasites in children, most of them polyparasited [9].

One of the interesting aspects of this interaction is the parasitism influence in cellular response to $M$. tuberculosis. Some in vitro studies sugested that parasited individuals had less effective cellular response compared to non parasited $[10,11]$, while other authors did not find any relation between parasitism and a positive result to tuberculin skin test (TST) in parasited individuals [12].

In the present study, we evaluated the prevalence of enteroparasitosis in tuberculosis patients, HIV-infected and non HIV infected, and we observed the influence of helminth presence in the response to TST and tuberculosis clinical outcomes.

\section{Material and Methods}

Region, Study Population and Time Period Studied

A review of 607 clinical files of patients from the Laboratório de Pesquisa Clinica em Micobacterioses (LPCM) at the Instituto de Pesquisa Clínica Evandro Chagas (IPEC) from Fundação Oswaldo Cruz (Fiocruz) was performed, from 2000 to 2006.

Patients with any tuberculosis presentation, determined by bacilloscopy and/or culture were included. In non confirmed cases, those who presented clinical criteria associated to a positive therapeutic proof were selected [13]. Patients that did not have stool tests for parasites were excluded. Variables Selected for the Study 
Variables selected for the study were: demographical (sex, age, occupation, and education), clinical (tuberculosis clinical presentation, treatment outcomes), and laboratorial (white blood cell and eosinophils counts, TST, and CD4). In the association with individuals' social class and tuberculosis, and presence of enteroparasitosis we have verified that the information "occupation" would not be suitable, as the activities are much diversified. Most occupations ranged from housekeeping, maids, servants, cleaner, among others. Therefore, in this study preference was given to analyze the relation between enteroparasitosis and social class through a proxy with educational degree.

\section{Techniques used in Stool Tests for Parasites}

The stool tests for parasites were performed at the Laboratório de Parasitologia from IPEC, and the techniques performed were: Kato Katz [14], Ritchie [15], and BaermannMoraes [16].

\section{Diagnostic Criteria}

HIV infection was determined by ELISA anti-HIV tests in two different blood samples, confirmed by an immunofluorescence assay or a Western blot [17].

\section{Data Analysis}

Initially, an exploratory analysis of the data was performed through description of frequencies, measures of central tendency and dispersion.

The association among categorical variables was verified through Pearson's chi-square test for independence (c2), or by a correction named Fisher's exact test if the table was formed by two lines and two rows. $P$-values $<0.05$ indicated statistically significant associations among the variables.

To verify the normality of continuous variables, Kolmogorov-Smirnov test was used, whose $P$-value $(p<0.05)$ corresponding to rejection of normality. Because of rejection of normality nonparametric tests were used. Mann-Whitney nonparametric test was used to verify differences between the continuous variable (eosinophils) distributions in both groups (TST result, anti-HIV test, presence or absence of helminthes and protozoa in stool tests for parasites).

Nonparametric Kaplan-Meier model was used to evaluate survival, related to tuberculosis treatment outcomes (favorable/unfavorable), and for the presence of some parasites. Thus, variables related to helminthes occurrence, protozoa occurrence, and specifically strongyloidiasis occurrence were tested.

If the variable presents a survival curve substantially different to the occurrence when compared to the absence, we could claim that the factor being tested is an important predictor of TB progression. Another way of stating this consists in applying Peto and Log-rank tests. $P$-values $<0.05$ would indicate that, statistically, the two survival curves differ significantly.
To describe which factors have an impact in helminthes and protozoa occurrence in tuberculosis patients, two models of logistic regression were performed. In the first model, helminthiasis occurrence was used as the outcome, while in the second model protozoa occurrence was used as the outcome. As selection criterion for the variables to both models, the variables related to the outcome by theorical relevance were used. However, to decrease the number of variables in the multivariate model, the variables with $P$-value $<0.2$ in the Type I Anova test and in the Wald statistic test were selected. This significance level was used because of small number of variables attain at $5 \%$ significance level. At last, the two final models are described, with their respective odds ratio (OR) and 80\% confidence intervals.

The analysis was performed in the statistic software Statistical Package for Social Sciences (SPSS) version 16.0. Survival and logistic models were performed with the software $\mathrm{R}$ version 2.6.0.

\section{Ethical Aspects}

The project was approved by the Institutional Review Board from the Instituto de Pesquisa Clínica Evandro Chagas.

\section{Results}

From 607 clinical records reviewed, 352 individuals met the study inclusion criteria and did not present any exclusion criteria. Other factors contributed to case exclusions, such as: diagnostic change, transfer to another hospital, absence of initial or end dates for the treatment. From the 607 clinical files reviewed, 327 were analyzed. Sociodemographic and clinical factors from the studied series are presented in Table 1.

The prevalence of enteroparasites observed was 19.6\%. Helminthes and protozoa prevalence in investigated patients were $10.1 \%$ and $9.8 \%$, respectively. The frequencies of parasites found were: S. stercoralis (7.3\%), E. histolytica (3.0\%), and G. lamblia (2.7\%). From seven polyparasitism cases, five occurred among protozoa, two among helminthes, and one in both. The prevalence of enteroparasitosis was similar in both sexes $(p=0.251)$.

Association Between Sociodemographic and Clinical/ Laboratorial Factors

Low educational level was observed among analyzed patients, most (43.6\%) was illiterate or had incomplete fundamental school; on the other hand, solely $8 \%$ attend or attended graduation schools.

There were no significant associations between the underlying disease (TB or HIV/TB), educational degree and age range according to stool test for parasites $(p=0.399 ; 0.945$ and 0.902 ). In addition, there was no significant association among TST result and the variables related to the presence of: helminthes, protozoa, and stool test for parasites result $(\mathrm{p}>0.5)$.

A significant association between eosinophils count and the stool test for parasites result and helminthes presence or 
Table 1. Distribution of sociodemographic, clinical and laboratorial factors from 327 TB patients (2000-2006).

\begin{tabular}{|c|c|c|}
\hline Sociodemographic variables & Categories & $(\%)$ \\
\hline \multirow[t]{2}{*}{ Sex } & Female & 38.2 \\
\hline & Male & 61.8 \\
\hline Age * & $42.44 \pm 12.60$ & - \\
\hline \multicolumn{3}{|l|}{ Educational degree } \\
\hline & Illiterate and FS incomplete & 43.4 \\
\hline & FS complete and HS incomplete & 32.4 \\
\hline & HS & 16.2 \\
\hline & Graduated & 8.0 \\
\hline \multirow{3}{*}{ Age range } & Up to 35 years & 34.3 \\
\hline & 36 to 46 years & 31.8 \\
\hline & $>46$ years & 33.9 \\
\hline Laboratorial variables & Categories & $(\%)$ \\
\hline \multirow[t]{2}{*}{ Stool test for parasites } & Positive & 19.6 \\
\hline & Negative & 80.4 \\
\hline \multirow[t]{2}{*}{ Helminthes } & Presence & 10.1 \\
\hline & Absence & 89.9 \\
\hline \multirow[t]{2}{*}{ Protozoa } & Presence & 9.8 \\
\hline & Absence & 90.2 \\
\hline \multirow[t]{2}{*}{ TST } & Non reactive (0-4 mm) & 20.2 \\
\hline & Reactive ( $\geq 5 \mathrm{~mm}$ in HIV+ and $>10 \mathrm{~mm}$ in TB) & 79.8 \\
\hline \multirow[t]{3}{*}{ White blood cell count } & Normal $(3,200-12,600)$ & 86.2 \\
\hline & Leukocytosis $(>12,600)$ & 4.6 \\
\hline & Leukopenia $(<3,200)$ & 9.2 \\
\hline Eosinophils* & $4.24 \pm 5.141$ & - \\
\hline \multirow[t]{2}{*}{ Eosinophils } & Eosinopenia (zero\%) and normal (1-6\%) & 78.9 \\
\hline & Eosinophilia (>6\%) & 21.1 \\
\hline \multirow[t]{2}{*}{ Tuberculosis Outcomes } & Favorable & 79.8 \\
\hline & Unfavorable & 20.2 \\
\hline \multirow[t]{2}{*}{ CD4 } & Up to 200 cells $/ \mathrm{mm}^{3}$ & 19.9 \\
\hline & $>200$ cells $/ \mathrm{mm}^{3}$ & 80.1 \\
\hline \multirow[t]{2}{*}{ Viral load } & Up to 100,000 copies & 74.9 \\
\hline & $>100,000$ copies & 25.1 \\
\hline
\end{tabular}

*Mean and Standard Deviation of continuous variables TST: Tuberculin Skin Test, CD4: CD4 cell counts, FS: Fundamental School, HS: High School.

absence was observed. The association between the eosinophilia and the presence of helminthes was significant both for HIV-negative TB cases ( $\mathrm{p}=0.001$ ) and for HIV-positive TB cases (p-0.000). Among HIV-negative TB patients presenting eosinophilia, $23.7 \%$ had helminthes vs. $45.2 \%$ of HIV-positive TB patients presenting eosinophilia.

Considering the survival of this cohort, we may observe that there is no significant difference $(P>0.05)$ between the survival curves of parasited and non parasited individuals. Patients' survival tends towards decreasing with long-term follow-up, regardless of the presence of parasitosis, even when helminthes, protozoa, and $S$. stercoralis are independently analyzed.

Variables potentially related to the outcomes, i.e., presence of helminthes and protozoa at the stool test for parasites, are presented in Table II. Solely the variable "eosinophils" presents a statistically significant association $(\mathrm{p}<0.001)$ with helminthes, all other associations are considered not significant.
After selection of the logistic model with the 12 variables theoretically related to the interest constructo (Table 2), once more, solely eosinophils (5\% significance level) describe helminthiasis occurrence. Patients presenting eosinophilia have 11.4 fold (95\% CI: 5.54-27.77) more chances of an unfavorable outcome (helminthes) than the group presenting eosinopenia or normal eosinophils count. Subsequently, an alternative model was performed (less conservative), with a 0.2 significance level, finding the following explicative variables for helminthiasis: sex, protozoa, and eosinophils (Table 3).

No variable presents statistical significance in the explicative model of protozoa occurrence, with a $5 \%$ significance level. At 20\% level, only the variable helminthes would explain the occurrence of protozoa (Table 3).

Male sex was a risk factor for helminthiasis, with 1.11 fold more chances of presenting helminthes than the women group. The absence of helminthes was a risk factor for protozoa, with 
Table 2. Variables distribution and association according to the outcome (helminthes and protozoa infection) in tuberculosis patients HIV-positive or HIV-negative.

\begin{tabular}{|c|c|c|c|c|}
\hline Variables $(\mathrm{N}=327) /$ Categories & Helminthes $(\mathrm{n}=33)(\%)$ & p-value* & $\operatorname{Protozoa}(n=32)(\%)$ & p-value* \\
\hline \multicolumn{5}{|l|}{ Sex } \\
\hline Male & 72.7 & 0.191 & 65.6 & 0.705 \\
\hline Female & 27.3 & & 34.4 & $\mathrm{CD} 4$ \\
\hline Up to 200 cells $/ \mathrm{mm}^{3}$ & 21.2 & 0.820 & 25.0 & 0.484 \\
\hline$>200$ cells $/ \mathrm{mm}^{3}$ & 78.8 & & 75.0 & \\
\hline \multicolumn{5}{|l|}{ Viral load } \\
\hline Up to 100,000 copies & 78.8 & 0.676 & 75.0 & 1.000 \\
\hline$>100,000$ copies & 21.2 & & 25.0 & \\
\hline \multicolumn{5}{|l|}{ Educational degree } \\
\hline Illiterate and FS incomplete & 54.5 & 0.459 & 37.5 & 0.905 \\
\hline FS complete and HS incomplete & 30.3 & & 34.4 & \\
\hline HS complete & 12.1 & & 18.8 & \\
\hline Graduation & 3.0 & & 9.4 & \\
\hline \multicolumn{5}{|l|}{ Age range } \\
\hline Up to 35 years & 30.3 & 0.323 & 37.5 & 0.765 \\
\hline 36 to 46 years & 24.2 & & 34.4 & \\
\hline$>46$ years & 45.5 & & 28.1 & \\
\hline \multicolumn{5}{|l|}{ Underlying Disease } \\
\hline $\mathrm{HIV}+\mathrm{TB}$ & 51.5 & 0.355 & 43.8 & 0.542 \\
\hline TB & 48.5 & & 56.3 & \\
\hline \multicolumn{5}{|l|}{ TST } \\
\hline Non reactive $(0-4 \mathrm{~mm})$ & 18.2 & 0.486 & 25.0 & 0.305 \\
\hline $\begin{array}{l}\text { Reactive ( } 35 \mathrm{~mm} \text { in } \mathrm{HIV}+\text { and } \\
>10 \mathrm{~mm} \text { in TB) }\end{array}$ & 81.8 & & 75.0 & \\
\hline \multicolumn{5}{|l|}{ Diagnostic Confirmation } \\
\hline Positive & 63.6 & 0.323 & 64.5 & 0.684 \\
\hline Negative & 36.4 & & 35.5 & \\
\hline \multicolumn{5}{|l|}{ TB Clinical Presentation } \\
\hline Pulmonary & 51.5 & 0.286 & 68.8 & 0.545 \\
\hline Extrapulmonary & 42.4 & & 25.0 & \\
\hline Disseminated & 3.0 & & 3.1 & \\
\hline Extrapulmonary and pulmonary & 3.0 & & 3.1 & \\
\hline \multicolumn{5}{|l|}{ Eosinophils } \\
\hline Eosinopenia (0\%) and normal (1-6\%) & 30.3 & $0.000^{*}$ & 71.9 & 0.360 \\
\hline Eosinophilia (>6\%) & 69.7 & & 28.1 & \\
\hline \multicolumn{5}{|l|}{ White blood cell count } \\
\hline Normal $(3,200-12,600)$ & 93.9 & 0.376 & 90.6 & 0.426 \\
\hline Leukocytosis $(>12,600)$ & 3.0 & & 0 & \\
\hline Leukopenia $(<3,200)$ & 3.0 & & 9.4 & \\
\hline \multicolumn{5}{|l|}{ Helminthes } \\
\hline Presence & NA & NA & 3.1 & 0.168 \\
\hline Absence & NA & NA & 96.9 & \\
\hline \multicolumn{5}{|l|}{ Protozoa } \\
\hline Presence & 3.0 & 0.168 & NA & NA \\
\hline Absence & 97.0 & & NA & NA \\
\hline
\end{tabular}

${ }^{*}$ p-value $<0.05$ at $\chi 2$ test. NA: Not applicable, FS: Fundamental School, HS: High School, TST: Tuberculin Skin Test, CD4: CD4 cell counts, TB: Tuberculosis. 
Table 3. Model analyzing factors of influence in the outcome of helminthes and protozoa in tuberculosis patients HIV-infected and not infected, with follow-up from 2000-2006 (N=327).

\begin{tabular}{lcc}
\hline Outcome (Presence X Absence) & Helminthes OR (80\% CI) & Protozoa OR (80\% CI) \\
\hline Sex & $2.11(1.45-3.08)$ & - \\
$\quad$ Male & 1.00 & - \\
$\quad$ Female & - & $3.77(1.58-9.00)$ \\
Helminthes & - & 1.00 \\
$\quad$ Absence & & - \\
$\quad$ Presence & $5.86(2.38-14.41)$ & - \\
Protozoa & 1.00 & - \\
$\quad$ Absence & & - \\
$\quad$ Presence & $14.14(9.91-20.18)$ & - \\
Eosinophils & 1.00 & \\
$\quad$ Eosinophilia & & \\
$\quad$ Eosinopenia and normal &
\end{tabular}

2.77 fold more chances of presenting protozoa than the group presenting helminthes. The absence of protozoa was a risk factor for helminthes, with 4.86 fold more chances of presenting helminthes than the protozoa group. Eosinophilia was a risk factor for helminthes, with 13.14 fold more chances than the eosinopenia or normal eosinophils count groups.

\section{Discussion}

The impact of helminthic infection on TST result, as well as on the tuberculosis clinical outcome (prognosis) is still controversial. Recent in vitro studies showed significant correlations between helminthic infections and tuberculosis [10,18-21]. In this study, initially, we evaluated the prevalence of enteroparasitosis in tuberculosis patients, HIV-infected or non infected, and we found a prevalence of helminthes similar to that observed by other authors, Strongyloides stercoralis being the most frequent parasite [10, 20]. However, the series from the other authors were composed exclusively by individuals with pulmonary tuberculosis. When we compare with the study performed by [11], we may consider our prevalence, as well as different parasites observed, significantly low. This could be explained by the population studied (Africa), where the number of intestinal parasitosis cases is knowingly higher.

There was no association between enteroparasitosis and social class or sex in our study, neither in Ludwig et al. [22] that observed a trend to intestinal parasitosis prevalence decrease, concurrent to the increase of basic sanitation, making evident an inverse relation between the prevalence of positive tests and the population with access to water and sewerage system. This could explain, at least partially, our low prevalence, as our patients live in Rio de Janeiro with better sanitation conditions [6].

Our study found statistical significance between eosinophilia and stool test for parasites result and between eosinophilia and helminthes presence or absence, both for HIV-negative or positive TB patients. Kaminsky et al. [23] and
Tristão et al. [20] observed, as we did, that intestinal infection by helminthes in HIV-positive patients resulted in immune responses involving eosinophilia.

In our study, we tried to verify whether there was a significant association between helminthic infections and response to TST, and in tuberculosis clinical outcome. No significant association was observed between TST result and presence of helminthes in tuberculosis patients, HIV-infected or non infected. Elias et al. [11] in a study in Ethiopia did not observe this association in patients with pulmonary tuberculosis, although TST reactivity has been greater in individuals treated with anti-helminthic drugs compared to placebo group. In a second step of this same study, the authors stimulated cellular response in vitro with PPD (Purified Protein Derivative) and found a significant association in individuals treated with placebo.

In our study there was no difference in survival among individuals with or without enteroparasites, which is consistent with Brown et al. [12] findings, suggesting that the presence of enteroparasitosis does not have a direct impact on survival.

After selection of the logistic model with the 12 variables theoretically related to the interest constructo, once more, solely eosinophils variable showed a relation to the outcomes (helminthes and protozoa in stool test for parasites). Reinforcing what has already been said above through another analysis (Mann-Whitney non parametric test) that eosinophils have a significant association with the presence of helminthes, suggesting that in the absence of a stool test for parasites, eosinophilia finding should indicate its performance and, occasionally, make anti-helminthic treatment [23].

Based in a literature review and in our own findings, intestinal parasites eradication, with consequent elimination of the immune modulation provoked by them, may lead to a positive tuberculosis outcome. Thus, more attention should be focused to prevention and treatment of helminthic infection, even before initiating bacterial or antiviral treatment. 
Our findings neither show an association between helminthic infection and a favorable TB outcome, nor between parasitism and TST response, unlike other in vitro studies. Apparently, experimental data do not correspond to the clinical findings.

\section{Acknowledgements}

We thank Dr Armando Schubach for valuable suggestions and Eduardo Machado for helping in the retrieval of patients' data. We also thank the team of the IPEC's Service for Documentation and Statistics, and Cristianne Marques and Simone Carvalho Neves from the Laboratory of Clinical Research in Mycobacteriosis, for the kind and efficient support in the search of the patients' files.

\section{References}

1. Ducati R.G., Ruffino-Netto A., Basso L.A., Santos D.S. The resumption of consumption. A review on tuberculosis. Mem Inst Oswaldo Cruz 2006; Rio de Janeiro. November Vol. 101(7): 697-714.

2. WHO. Report global tuberculosis control: surveillance, planning, financing, Geneva, 2007. World Health Organization.

3. Global Alliance for Tuberculosis Drug Development (homepage on the internet) USA, (acessado em julho de 2008). Disponível em: http://www.tballiance.org/home/home.php

4. WHO Report global tuberculosis control: surveillance, planning, financing, Geneva, 2004. World Health Organization.

5. Brasil. Ministério da Saúde. Secretaria de Vigilância em Saúde. Departamento de Vigilância Epidemiológica. Doenças infecciosas e parasitárias: guia de bolso / Ministério da Saúde, Secretaria de Vigilância em Saúde, Departamento de Vigilância Epidemiológica. - 4. ed. ampl.- Brasília: Ministério da Saúde, 2004.

6. DATASUS (homepage on the internet) Brasil, Departamento de Informática do SUS, Ministério de Saúde do Brasil (acessado em julho de 2008). Disponível em: http://tabnet.datasus.gov.br

7. Wady M.T.B.; Linhares-Carvalho M.I.; Salles-Costa R.; Valle J. e Castello-Branco L.R.R. Investigação dos aspectos nutricionais em homens abrigados em uma instituição filantrópica envolvida em surto de tuberculose.Bol.Pneumol Sanit 2004; 12(1): 11 16.

8. WHO. Report of an informal consultation on hookworm infection and anemia in girls and women. Geneva, 2002. World Health Organization.

9. Campos R., Briques W., Belda Neto M.,et al. Levantamento multicêntrico de parasitoses intestinais no Brasil. Rhodia - Grupo Rhône-Poulenc, São Paulo, 1988.
10. Co T.R.; Hirsch C.S; Toossi Z.; Dietze R and Ribeiro-Rodrigues R. Intestinal helminth co-infection has a negative impact on both anti-Mycobacterium tuberculosis immunity and clinical response to tuberculosis therapy. British Society for Immunology, Clinical and Experimental Immunology 2006, 147: 45-52.

11. Elias D.; Wolday D.; Akuffo H.; Petros B.; Bronner U.; Britton S.; Hansen A. Effect of deworming on human $\mathrm{T}$ cell responses to mycobacterial antigens in helminth-exposed individuals before and after bacilli Calmette-Guerin (BCG) vaccination. Clin Exp Immunol 2001; 123:219 \pm 225 .

12. Brown M., Miiro G., Nkurunziza P., Watera C., Quigley M.A., Dunne D.W., Whitworth J.A.G., Elliott A.M. Schistosoma mansoni, nematode infections, and progression to active tuberculosis among HIV-1-infected Ugandans. Am J Trop Med Hyg 2006; 74:819-25.

13. Brasil, Ministério da Saúde. Plano Nacional de Controle da Tuberculose. Brasília: FUNASA; 1999. p. 184

14. Katz N.; Chaves A.; Pellegrino J. A simple device for quantitative stool thick smear technique in schistosomiasis mansoni. Rev Inst Med trop S Paulo 1972; 14:397-400.

15. Ritchie L.S. An ether sedimentation technique for routine stool examinations. Bulletin of the United States Army Medical Department 1948; Washington, v.8, p.326.

16. Moraes R.G. Contribuição para o estudo do Strongyloides stercoralis e da estrongiloidíase no Brasil. Rev Saúde Publica 1948; 1: 507624.

17. ANVISA/MS (homepage on the internet) Brasil, Exames de HIV e AIDS, Ministério de Saúde do Brasil (acessado em julho de 2008). Disponível em: http://www.aids.gov.br

18. Diniz LM.; Zandonade E.; Diatze R.; Pereira F.E.; Ribeiro-Rodrigues R. Short report: do intestinal nematodes increase the risk for multibacillary leprosy? Am. J. Trop. Med. Hyg 2001; 65(6): 852-4.

19. Stewart G.R.; Boussinesq M.; Coulson T.; Elson L.;Nutman T.; Bradley J.E. Onchocerciasis modulates the immune response to mycobacterial antigens. Clin Exp Immunol 1999; 117:517-23.

20. Tristão-Sá R.; Ribeiro-Rodrigues R.; Johnson L.T.; Pereira F.E.L; Dietze R. Intestinal nematodes and pulmonary tuberculosis. Rev. Soc. Bras. Med. Trop 2002; 35 (5): 533-535.

21. Elias D., Mengistu G., Akuffo H., Britton S. Are intestinal helminthes risk factors for developing active tuberculosis? TropMed Int Health 2006; 11:551-8.

22. Ludwig K.M.; Frei F.; Alvares F.F. e Ribeiro-Paes J.T. Correlação entre condições de saneamento básico e parasitoses intestinais na população de Assis, Estado de São Paulo. Revista da Sociedade Brasileira de Medicina Tropical 1999; 32(5):547-555.

23. Kaminsky R.G.; Soto R.J.; Campa A.; Baum M.K. Intestinal Parasitic Infections and Eosinophilia in an Human Immunedeficiency Virus Positive Population in Honduras.Mem Inst Oswaldo Cruz 2004; Rio de Janeiro, November Vol. 99(7): 773-778, 773. 